\title{
El periódico católico De Pie. Iglesia, educación y peronismo durante la Revolución Libertadora
}

The catholic newspaper De Pie. Church, education and peronism during the Revolución Libertadora

\author{
Mariana Paola Vicente marianavicente93@gmail.com
}

https://orcid.org/0000-0002-3011-8355

Centro de Investigaciones y Transferencia Golfo San Jorge; Consejo Nacional de Investigaciones científicas y técnicas/Universidad Nacional de la Patagonia San Juan Bosco

\section{Resumen}

La prensa católica puede ser interrogada de diversas formas: como producto cultural, actor político o fuente histórica. El objetivo en este artículo es demostrar el posicionamiento político de un periódico católico de la ciudad de Comodoro Rivadavia denominado De Pie a través del tema educativo, aunque no exclusivamente, en el contexto del derrocamiento del peronismo y el marco internacional de la guerra fría, donde el anticomunismo articulaba con el 
antiperonismo. Se expondrá porqué, para el periódico, la educación se torna fundamental para la defensa de la democracia, en condena de lo que había sido la "dictadura" y como barrera frente a la intromisión del totalitarismo, al tiempo que la libertad de enseñanza ponga fin al monopolio estatal y permita mayor proyección de las instituciones educativas católicas.

Palabras clave: Catolicismo; educación; peronismo; revolución libertadora; Comodoro Rivadavia.

\section{Abstract}

The Catholic press can be questioned in various ways: as a cultural product, political actor or historical source. The objective in this article is to demostrate the political positioning of a Catholic newspaper in the city of Comodoro Rivadavia called "De Pie" through the educational theme, although not exclusively, in the context of the overthrow of Peronism and the international framework of the "Cold War", where anti-communism articulated with antiPeronism. It will be explained why, for the newspaper, education becomes essential for the defense of democracy, in condemnation of what had been the "dictatorship" and as a barrier against the intrusion of totalitarianism, at the same time as the "freedom of education" that puts an end to the state monopoly and allow greater projection of Catholic educational institutions.

Keywords: Catholicism; education; peronism; revolución libertadora; Comodoro Rivadavia.

En abril de 1956 se publicó el primer número del periódico católico De Pie en la ciudad de Comodoro Rivadavia con el siguiente titular: "Pedimos: libertad y democracia para la enseñanza". Desde sus páginas se bregaba por la libertad de enseñanza cuando el gobierno de la Revolución Libertadora (1955-1958) proponía la vuelta a la Ley 1420 de educación común, luego de lo que había sido la experiencia educativa del peronismo. Un objetivo de este artículo es demostrar el posicionamiento político del periódico a través del tema educativo, aunque no exclusivamente, en el contexto del derrocamiento del peronismo y el marco internacional de la guerra fría, donde el anticomunismo articulaba con el antiperonismo. Siguiendo a Héctor Borrat (1989), analizaremos a De Pie como un actor del sistema político, en conflicto con otros actores y portador de una ideología. 
Considerando además, la validez que tiene la prensa católica (1) como objeto de estudio y las variantes de lecturas que permite, al poder ser interrogada como producto cultural, actor político y fuente histórica (Lida y Fabris, 2016: 12), otro objetivo es analizar al De Pie como un portavoz de los intereses de la Iglesia e integrante de la familia católica comodorense de mediados de siglo XX.

\section{De Pie y el peronismo en el contexto de la guerra fría}

El Golpe de Estado de 1955 dio inicio al periodo de la autodenominada Revolución Libertadora que se extendió hasta mayo de 1958. Las posturas de los países del bloque comunista y de Estados Unidos frente al cambio de régimen en Argentina dan cuenta de la impronta anticomunista de los gobiernos que conformaron la libertadora. Con el golpe no solo se produjo un distanciamiento con la Unión Soviética (URSS) y el resto de los países de Europa del Este, sino que sirvió de excusa para perseguir a los militantes comunistas locales, ya que el comunismo podría ser terreno fértil para el peronismo proscripto. Resulta significativo lo dicho por María Valeria Galván (2018) respecto a que el anticomunismo articulaba bien con el antiperonismo de los intelectuales argentinos, quienes compartían con sus pares europeos los ideales de la defensa de la libertad y la crítica al totalitarismo. Así, la asociación del peronismo al mapa de los totalitarismos del siglo $\mathrm{XX}$, en el que también estaban los comunismos, favorecía dicha articulación.

En cuanto a lo educativo, la decisión del gobierno provisional fue la vuelta a los principios de la Ley 1420 de educación común. La preocupación por parte de los católicos era la obligatoriedad de la educación laica y el monopolio estatal sobre la administración de la misma. Es importante recordar que la ley, fundamento del sistema educativo argentino, había instaurado la educación laica, obligatoria y gratuita en las escuelas públicas en 1884, permitiendo la enseñanza de religión luego del horario de clase.

En ese contexto comienza a editarse el periódico católico De Pie. La Organización Estrada era la encargada de su edición y se ubicaba en el barrio General Mosconi, cerca del centro de la ciudad. Tenía por finalidad: "Propender a la defensa y propagación de los principios morales y culturales que fundamentan toda la civilización cristiana" (De Pie, 27/04/1956: 4). Sus miembros debían respetar los principios que fueron aprobados en asamblea y estaban organizados por un estatuto. Se reunían semanalmente tratando diversas temáticas y llevando adelante actividades culturales que eran regidas por una Comisión Directiva. El primer principio establecía: "La 'Organización Estrada' propugna únicamente una moral dogmática 
cristiana. Los adherentes profesan la religión católica, apostólica y romana, admitiendo a los que practiquen cualquier otro culto cristiano". Luego declara que fomentará el desarrollo de la cultura en todos los órdenes, mientras no se desvirtúen los principios de la moral, y propenderá a la superación de los valores espirituales y materiales que tiendan a su constante perfeccionamiento (De Pie, 25/05/1956: 4). En el estatuto aparece la siguiente explicación:

La "Organización Estrada" no tiene carácter político y se abstendrá de actuar en ese campo [...] La actuación de sus socios en otras actividades, asociaciones o partidos políticos es asunto puramente personal y no puede comprometer la responsabilidad de la "Organización Estrada"; pero sus dirigente no podrán ser los de un partido político"(De Pie, 22/06/1956: 4).

Respecto de su posición en la esfera pública afirmaban: "Nosotros no somos, y que se entienda de una vez, ni peronistas ni antiperonistas, ni formamos una obscura y disimulada agrupación con exclusivos fines políticos", separándose de cualquier tradición política partidaria. Asumían además, que su voz incomodaba y sacudía a "dormidas conciencias; dormidas cuanto cristianas, dormidas patrióticamente" (De Pie, 01/1957: 1).

El 14 de septiembre de 1956 se realizó un acto en el salón del Club Huracán con el fin de recordar a José Manuel Estrada, al cumplirse un nuevo aniversario de su fallecimiento el día 17 (El Rivadavia, 14/09/1956: 2). Su destacada trayectoria como intelectual católico a finales del siglo XIX dentro del movimiento opuesto a las políticas laicistas implementadas a nivel nacional, fueron motivos suficientes para que una organización católica con dichos objetivos lleve su nombre: "Organización Estrada se espeja en la limpia y prócer figura de José Manuel Estrada cuyas virtudes cristianas y cívicas se esfuerzan en copiar los socios de nuestra Asociación" (De Pie, 01/1957: 1). Él pensó la educación, la familia y otras instituciones como instrumentos para formar ciudadanos morales, virtuosos, instruidos en la religión (Martín, 2012).

Pensamos al periódico De Pie como un actor político en consonancia con lo propuesto por Héctor Borrat (1989), portador de una ideología expresada en su línea política, que define la inclusión o exclusión de temas, como la jerarquización y los comentarios sobre los mismos, teniendo como ámbito de actuación la influencia, es decir, la capacidad de afectar el comportamiento de ciertos actores en un sentido favorable a sus propios intereses, y siendo a la vez objeto de la influencia de los otros. En este sentido, De Pie formaba parte de la familia católica comodorense junto a organizaciones civiles como las Ligas de Padres y las Ligas de Madres de Familia, la Congregación Salesiana y el Partido Demócrata Cristiano. Estos sectores se manifestaron en la prensa local de la ciudad pidiendo por la libertad de 
enseñanza, en sintonía con el discurso de la Iglesia, mientras que otros actores no identificados como católicos, lo hicieron en defensa de la ley 1420.

Una vez derrocado el peronismo, como forma de condena a la acción educativa de la "dictadura" y a modo de enfrentar las pedagogías totalitarias, apareció la preocupación por una educación para la libertad. Una de las principales pautas que conectarían al gobierno libertador con el antiperonismo intelectual, fue la idea de la desperonización popular, desde la prohibición de nombres y símbolos ligados al peronismo, hasta los constantes planteos sobre la necesidad de una educación democrática (Vicente, 2018). En este sentido, como afirma Adrian Ascolani (2000) uno de los objetivos que persiguió la desperonización en la educación fue la despolitización de la escuela. De Pie reclama que la Revolución Libertadora no estaba llevando adelante uno de sus principios, el de liberar la enseñanza y despolitizar al estudiantado y a la escuela, los cuales se vieron corrompidos como resultado del "imperio de la política" (De Pie, 27/04/1956: 2) impuesto en los años precedentes:

La revolución que estamos viviendo se proclama revolución libertadora: por lo tanto el laicismo obligatorio no pudo ser objetivo y menos quedar definitivamente si por error se ha incurrido en él. O será que la filosofía no cuenta? El laicismo obligatorio es ofensivo de las instituciones democráticas; la revolución debe liberarnos de este brote totalitario así como deben hacer justicia en otras situaciones de la vida nacional (De Pie, s/f: 2).

El término totalitarismo amplió su alcance como fruto de las discusiones internacionales de la guerra fría, abarcando prácticas e ideas no ligadas al fascismo o al comunismo: "No le queremos imponer nada; eso es propio de los totalitaristas. Nosotros sólo lo invitamos a que piense y medite" (De Pie, 27/04/1956: 2). Si hasta el fin del conflicto bélico mundial primaron dos grandes líneas anti-totalitarias: una centrada en una oposición al fascismo y la otra al comunismo, con la reconfiguración del mapa internacional una vez finalizada la guerra, la segunda ganó fuerza, subsumiendo a la primera. Se produce entonces una reinterpretación del concepto de democracia, "que no puede comprenderse sin considerar la irrupción totalitaria como fantasma rector de la política internacional y la particular adaptación de ese concepto a la situación argentina..." (Morresi y Vicente, 2017: 11). A la vez, el concepto de democracia sufrió una bifurcación, como consecuencia de su reinterpretación a luz de lo que había sido el gobierno peronista: había una democracia deseable, que era liberal, republicana y limitada y otra execrable; la populista, desmesurada y potencialmente totalitaria. Así el fenómeno totalitario comenzó a entenderse como un peligro que no sólo acechaba a los regímenes democráticos, sino que anidaba en ellos. "El advenimiento de la guerra fría condujo

Question, Vol. 1, N. ${ }^{\circ}$ 63, julio-septiembre 2019. ISSN 1669-6581

Instituto de Investigaciones en Comunicación | Facultad de Periodismo y Comunicación Social | Universidad Nacional de La Plata La Plata | Buenos Aires | Argentina

Página 5 de 18 
a que la cuestión del totalitarismo se exacerbase y se convirtiese en el problema político y ético por antonomasia del siglo XX" (Morresi y Vicente, 2017: 4). De Pie manifiesta su preocupación alertando acerca de las posibilidades de intromisión del totalitarismo y advirtiendo la necesidad de enmendar errores, sobre todo luego de los tiempos "felizmente superados":

Un régimen que desconoce las libertades democráticas, que establece un sistema anticonstitucional de autoritarismo, que anula las normas jurídicas, es la mejor y la más efectiva "quinta Columna" que de la penetración del totalitarismo pueda esperarse y que el totalitarismo puede desear. [...] Con la experiencia acumulada de tiempos felizmente superados es que se deben evitar errores y es que se deben enmendar rumbos o rectificarlos. [...] Las "quinta- columnas" organizadas desde las embajadas de países totalitarios, están interesados en propiciar los regímenes despóticos, las dictaduras, los golpes de estado y las revoluciones de bolsillo o de palacios. Les interesa que los hombres y los pueblos se debatan en momentos de anarquismo y desesperación, porque ese es el caldo de cultivo de sus menguadas ambiciones (De Pie, 27/04/1956: 1).

En una reflexión acerca del fracaso de antiguas democracias, De Pie concluye que si la Democracia sin justicia social ha desembocado primero en el Capitalismo, y después, por reacción, en los totalitarismos, la Democracia sin fundamento religioso y moral ha de parar en el materialismo, primeramente, que a su vez dará origen a nuevos sistemas totalitarios (De Pie, 10/1956: 1).

Puede entenderse que si el sistema democrático propuesto por el liberalismo, que dejó a un lado las necesidades de las masas populares, desembocó en el peronismo; la ausencia del fundamento religioso y moral conllevará a nuevos totalitarismos, como por ejemplo el comunismo.

En esa línea, el problema político más importante para el gobierno de la libertadora era que hacer con el peronismo. Para el antiperonismo más radicalizado, el peronismo había sido un régimen nazi- fascista al que había que erradicar definitivamente, como partido y como identidad política, ya que era considerado enemigo del sistema democrático y de la nación. Por ello, la desperonización persiguió dos objetivos: desarmar los resortes totalitarios de las instituciones del Estado, e ilustrar a aquellos sectores sociales identificados con el peronismo, de que habían sido engañados y orientarlos a apreciar los valores democráticos tradicionales de la cultura argentina, que la revolución representaba (Spinelli, 2005). En el mandato de 
Pedro Eugenio Aramburu la desperonización fue definida como el objetivo básico en pos de desmontar el "aparato totalitario", convirtiéndose en el tema central del clima político.

En la Patagonia, la colaboración de la sociedad civil le otorgó un manto de legitimidad a las acciones represivas encabezadas por los interventores militares, quienes fueron auxiliados por la policía y respaldados por Comisiones Investigadoras provinciales y sub comisiones que sugirieron medidas, opinaron y dictaminaron en numerosas causas (2). Los destinatarios eran aquellos con incidencia sobre la población: el personal de las escuelas como directores y maestras estuvieron en el centro de la atención, conjuntamente con los jueces de paz y en menor medida, directores de hospitales y gremialistas (Ruffini, 2016). Aquí, la crítica del periódico hacia las acciones represivas llevadas adelante por el gobierno provisional en nombre de la democracia:

Tanto más peligroso es aún, que un Estado sudamericano cualquiera, adopte una política totalitaria, niegue derechos y libertades, tiranice a su pueblo, estrangule toda garantía y persiga, arreste, torture o destierre a sus adversarios. Contra este tipo de gobiernos, es también que debe ejercerse acción por parte de cualquier otro Estado, porque el implantamiento de tales métodos antidemocráticos auspicia y estimula la propagación del totalitarismo (De Pie, 07/1956: 3).

Otro cuestionamiento era la política respecto del sector obrero: "Mientras la causa de la Revolución no se gane la masa obrera, no habrá garantías ni esperanzas de una pacífica estabilización" (De Pie, 11/05/1956: 3). Reconocen que este sector vivió durante los últimos diez años "una experiencia nueva y original" y entienden que la desintegración sindical: en el cese de funciones de sus dirigentes, en la imposición arbitraria de intervenciones, en la renovación de convenios sin la participación activa de los dirigentes sindicales, las cesantías, suspensiones y otras; colaboran en el resentimiento hacia la reorganización del país de una masa obrera que se encuentra "anarquizada, insatisfecha, desconcertada y con gran vacío afectivo por la ausencia del que fuera su líder", situación sobre la cual el socialismo y el comunismo "ya tienen sus cálculos" (De Pie, 11/05/1956: 1).

El régimen depuesto quiso desnaturalizar el alma nacional. ¿Y a que recursos apeló? A los mismos a los que ahora está apelando el socialismo. ¿Y a qué conclusiones llegó? El ataque al clero y a la Iglesia, es la primera etapa de la posterior lucha total. O totalitaria, para ser más precisos. [...] El catolicismo argentino, identificado con nuestra historia, no desde ayer, sino desde los primeros albores de la nacionalidad e inmensamente mayoritario en todo el pueblo 
de la República, merece también respeto. El catolicismo no pretende ni quiere imposiciones. Desea libertad para enseñar y difundir su doctrina. ¿Por eso se lo combate? (De Pie, 13/04/1956: 2).

Las transformaciones producidas por la experiencia peronista y la cuestión de la proscripción o integración del peronismo, eran parte de las tensiones que atravesaban la identidad católica. Para Claudia Touris (2007: 348) estaban relacionadas más directamente con "el quiebre de una identidad católica que estaba dejando de significar lo mismo para los diferentes sectores que la conformaban", siendo redefinida cada vez más en términos políticos que religiosos. Para ella, tres ejes estructuraron la estrategia de la Iglesia en dicha coyuntura: la forma de encarar la vinculación con el movimiento obrero, el afán por restaurar el principio de autoridad erosionado al interior por el enfrentamiento con Perón y las exigencias ante el poder político. El periódico se hace cargo del cuestionamiento del papel de la Iglesia en la política y expone algunos argumentos. En una nota alega que la Iglesia en los veinte siglos de su existencia "ha tenido que salir al campo de lo temporal, en todos los casos que las situaciones sociales y políticas abandonaron el terreno puramente temporal para inmiscuirse en el aspecto moral y espiritual de la humanidad". En una época de desconcierto, como lo es el siglo XX, la Iglesia ha salido una vez más para orientar las opiniones confundidas y aclarar las responsabilidades que le competen a su función rectora (De Pie, julio 1956: 1). Y se preguntan:

¿Por qué los mismos que hoy acusan a la Iglesia de inmiscuirse en política y la censuran por ello, son los que en otros momentos la acusaban de no haberse inmiscuido durante el régimen depuesto hasta que éste la atacó directamente? ¿Entonces, debe o no debe la Iglesia actuar en política? [...] Veinte siglos hace que la Iglesia condena el divorcio, que defiende el derecho de la persona humana, la libertad de los padres en cuanto a la educación de sus hijos, etc. Ahora resulta que partidos políticos e instituciones, algunas de las cuales no vienen ni siquiera del siglo pasado, la tachan de invadir el campo que les corresponde a ellos. Son los mercaderes del confusionismo (De Pie, 8/06/1956: 1).

Meses después interpelan a los actores políticos partidarios acerca de su postura aparentemente "anticlerical", la que en parte comprenden: "Si por 'anticlericalismo' ellos entendieran la prescindencia de los miembros del clero en 'los manejos' estaríamos de acuerdo con ellos". Sin embargo, entienden que detrás de ese anticlericalismo se esconde un verdadero anticristianismo:

Question, Vol. 1, N. ${ }^{\circ} 63$, julio-septiembre 2019. ISSN 1669-6581

Instituto de Investigaciones en Comunicación | Facultad de Periodismo y Comunicación Social | Universidad Nacional de La Plata La Plata | Buenos Aires | Argentina

Página 8 de 18 
No es cierto, señores demócratas progresistas, señores socialistas, señores comunistas, señores de la Unión Radical que, según lo que hasta ahora ustedes han dicho públicamente, ustedes resultan, no sólo anticlericales, sino "anticristianos"? No es cierto que al defender la enseñanza laica, el divorcio y el monopolio estatal en la educación, lo que ustedes pretenden es la no vigencia del cristianismo en la educación, en la familia y en la vida social? ... Entonces señores sean francos, digan que son "anticristianos" y no simplemente "anticlericales (De Pie, 10/1956: 1).

En defensa de la familia y de los deberes y derechos de los padres sobre la educación de sus hijos, De Pie dedicará gran parte de su superficie editorial a reclamar por la libertad de enseñanza y a explicar la importancia de terminar con el monopolio estatal en el ámbito educativo, en contra del totalitarismo y a favor de la democracia. El siguiente apartado aborda esta cuestión.

\section{De Pie y las disputas por la educación}

La educación ha sido históricamente un campo de disputa y el periodo que siguió a la caída del peronismo no fue una excepción. Los años que transcurren desde 1955 hasta 1958, se observa en la prensa local que la educación era uno de los temas más relevantes de la agenda política y social: reclamos por la falta de construcción edilicia que dejaba a muchos fuera de las aulas; la necesidad de una institución de educación superior; hasta expresiones de diferentes sectores que buscaban imponer una visión acerca de cómo debía regirse el sistema educativo del país. Primero fue la intención del gobierno provisional de volver a la ley 1420 lo que generó variadas manifestaciones en los diarios locales. Católicos y no católicos salieron posicionarse a favor o en contra de la ley de educación que había sido promulgada inicialmente a fines del siglo XIX (3).

Luego, ya en el gobierno de Arturo Frondizi, estalló el conflicto por las universidades libres. Este, había tenido sus primeros enfrentamientos a inicios de 1956, cuyas violentas manifestaciones terminaron provocando la renuncia del entonces ministro de Educación Atilio Del Oro Maini, quien había firmado el decreto 6403 en diciembre de 1955, que permitía a la iniciativa privada otorgar títulos habilitantes. El periódico De Pie ha sido participe activo en estas disputas por la educación, y es propósito de este segundo apartado analizar su posición como portavoz católico. 
El gobierno revolucionario debía enfrentar varios dilemas en el ámbito educativo. Uno de ellos era que ley regiría el sistema, otro residía en resolver las reincorporaciones de aquellos agentes educativos que habían sido cesanteados por el peronismo, al tiempo que las comisiones investigadoras daban cuenta de la adscripción de muchos al régimen depuesto, condición que los colocaba inmediatamente afuera de sus puestos de trabajo. Pasados los conflictos de principios de 1956 por el decreto nro. 6403 sobre la iniciativa privada, De Pie da cuenta de un diálogo entre el Obispo de Bahía Blanca y el vicepresidente Isaac Rojas:

El Obispo, entonces, hizo observar que el Sacerdote no solamente debe intervenir en problemas meramente espirituales, sino también en cuestiones de carácter mixto, donde lo espiritual está íntimamente unido con lo temporal, y citó el caso de la libertad de enseñanza que un sector muy grande de la población ha pedido, siéndole negado este derecho. Porque la ley laica es extranjerizante y al (sic) tradición argentina comienza antes de 1884 (De Pie, s/f: 1).

A lo que Rojas respondió que "el espíritu de la Revolución era que los problemas fundamentales se trataran después de las elecciones y que por lo tanto había que tener paciencia". El Obispo entonces contesta que la si la revolución era libertadora debía también liberar del monopolio del Estado en materia de enseñanza. En este punto es pertinente ver que entienden desde la publicación católica por monopolio estatal sobre la enseñanza:

Es la absorción, el acaparamiento del sistema educativo por el Estado: pero, en general, estas se pueden reducir a tres principales: O bien sólo el Estado puede fundar o sostener escuelas [...] o bien sólo pueden enseñar quienes han obtenido los diplomas del Estado [...] o, finalmente, sólo tienen valor los títulos cuando se ha sometido los alumnos a los planes, programas y exámenes del Estado (De Pie, 13/04/1956: 1-2).

En cada uno de los ítems expresados hacen acotaciones donde exponen los límites que tiene el Estado para sostener el sistema educativo, por ejemplo, acerca de la fundación de escuelas advierten que no existe tal monopolio en el país, ya que el Estado no tiene como absorber "Ios centenares de miles de alumnos que se educan en escuelas particulares":

Hoy son más de mil las escuelas religiosas de la Nación, las cuales atienden a más de 300.000 alumnos. Gracias a estas escuelas católicas desperdigadas a través de todo el 
territorio de la República pudo neutralizarse parcialmente en nuestra patria, el satánico intento masónico de laicizar la sociedad argentina (De Pie, 8/06/1956: 2).

Aquella ley "extranjerizante" que proponía la educación religiosa por fuera del horario de clases fue interpretada como una derrota del sector católico ante el embate liberal de finales del siglo XIX. Lucía Lionetti (2006) examina hasta qué punto la enseñanza propuesta por esta ley se alejaba del modelo de enseñanza religiosa. Más que una confrontación entre los valores difundidos por el Estado liberal y por la Iglesia lo que existió fue una convivencia. Los valores que se pretendían transmitir en la escuela eran compatibles con los principios católicos, que se develaron funcionales para el armado del dispositivo normativo de la enseñanza laica. Para ella, tanto los sectores liberales como la Iglesia Católica aprovecharon la disputa por lo educativo para cohesionarse internamente y posicionarse de esa manera en el escenario político.

Hacia los años treinta el sistema educativo perdió gradualmente su carácter laico, a partir de la hegemonía de los intelectuales nacionalistas antiliberales, sectores próximos al tradicionalismo católico y al fascismo, que pasaron a tomar control de la educación. En 1943 el decreto 18411 instauró la materia de religión en las escuelas, y para 1947 se transformó en la ley de enseñanza religiosa, aprobada por una amplia mayoría de diputados. En 1954 fueron suspendidas las materias de religión y moral en las escuelas públicas (Caimari, 2010). Justamente la educación religiosa fue uno de los temas que había tensionado la relación entre la Iglesia y el gobierno hacia finales del primer peronismo, sumado al avance de otras formas religiosidad (pentecostalismo y el espiritismo), y la sacralización de las figuras de Perón y de Eva Duarte, sobre todo luego de su muerte en 1952. A continuación presentamos un extenso fragmento del mes de abril del 56 :

¿Qué opinaría usted padre de familia, si el estado determinara, reglamentara e impusiera, el tipo de lectura exclusiva que debiera leer su hijo; el cine o teatro exclusivo a que debiera concurrir; la radio exclusiva que debiera escuchar; el partido político exclusivo al que debiera pertencer? Etc (no hay exageración! No olvide que hasta hace muy poco nos impusieron: prensa única, radio única, ideología política única. Entonces usted no podría dejar de opinar que eso es tiranía y que el estado abusivamente se apropia de sus irrenunciables e inalienables derechos naturales de padre, verdad?

Pues bien que opina ahora del estado que determina, reglamenta e impone la "escuela única laica" y obligatoria? (no confunda los institutos privados no subvencionados). Tiene usted claro concepto de lo que es el laicismo? Laicismo en la abolición absoluta y total de la idea de Dios

Question, Vol. 1, N. ${ }^{\circ}$ 63, julio-septiembre 2019. ISSN 1669-6581

Instituto de Investigaciones en Comunicación | Facultad de Periodismo y Comunicación Social | Universidad Nacional de La Plata La Plata | Buenos Aires | Argentina

Página 11 de 18 
en cualquiera de sus formas religiosas, llámese judía, protestante, católica, mahometana, budista etc. Laicismo es ateísmo. Laicismo es negación de Dios y laicismo escolar es negarle la posibilidad a su hijo que sepa de la existencia de un Ser Superior. Es decir que la "escuela laica" tiene una forma de pensamiento: forma sin Dios. Y una FORMA o forma única son dos términos iguales. ¿Por lo tanto, es democrático o totalitario este principio? ¿No le parece entonces que para no embanderarnos en posturas totalitarias y uniformistas, urge liberar la enseñanza, permitiendo el pleno ejercicio de los derechos individuales? (De Pie, 27/04/1956: 1).

De aquí nos interesa la forma de interpelar al lector como padre de familia, por lo tanto responsable de la educación y formación de sus hijos y poseedor natural de derechos inalienables e irrenunciables respecto de ellos. Sostenido, según argumenta Mariana Vazquez Lorda (2012), por la encíclica Rerum Novarum y la potestad de los padres acerca de la educación de sus hijos, siendo la familia una sociedad que precede al Estado, regida por el poder paterno, limitando así la intervención estatal. Hacen referencia al peronismo como forma política totalitaria, la cual impuso prensa única, radio única etc. Ven en la educación laica obligatoria impuesta por el Estado, una cierta continuidad de esa forma totalitaria, por lo que Ilaman la atención acerca de la urgencia de liberar la enseñanza. Al momento de denunciar el laicismo como ateísmo, consideran a diversas formas religiosas, cuando el pluralismo religioso había sido un punto de conflicto con el peronismo, como expusimos algunos párrafos atrás. En el final de la cita aparece un llamado a la reflexión acerca de si el laicismo en la escuela constituye un principio democrático o totalitario, dando a entender que la única manera de no encerrarse en posturas totalitarias es liberar la enseñanza (Autor/a y otro, 2017).

La libertad de enseñanza aboliría este imperio de la politica en los Institutos de Enseñanza; acabaría con ese núcleo clásicamente comunizante- a sueldo de la U.R.S.S--- afincados en los distintos cursos de cada una de las Facultades con mas de 20 años de "servicios continuados" en la misma aula, que nunca llegan a laurearse, porque no les interesa el título sino politizar el estudiantado! (De Pie, 27/04/1956: 2).

Para el periódico es de suma preocupación la politización del estudiantado que ejemplifican con varios titulares, tales como: "Invitase a una huelga de estudiantes"; "Detención de estudiantes"; "La Federación Universitaria propicia un paro el viernes". La política en las instituciones educativas es vista como vía privilegiada para el afianzamiento del comunismo, 
siendo la libertad de enseñanza la salida de las formas totalitarias, aislando a los jóvenes de la política. El comunismo es definido por De Pie como:

...un fenómeno humano de posesión diabólica, porque destruye, en el hombre y en la sociedad, cuanto ésta y cuanto aquel tienen de hombre y de Dios: por decirlo en síntesis, es ateo y materialista [...] Destruye y aniquila así lo más grande del hombre: su persona y, junto con ella, todos sus derechos y, por consecuencia, los de la familia, de la nación y de la sociedad (De Pie, 11/05/1956: 2).

El periódico no escapa a una época en la que el comunismo, como una de las formas del totalitarismo, era calificado como enemigo de la democracia y de la nación, el cual se encontraba presente en la sociedad, en la masa obrera, en el estudiantado y había que erradicar. Los católicos habían denunciado hacia finales de 1954 la infiltración comunista en la adhesión a Perón y de hecho consideraban al peronismo como "vehículo del autentico comunismo soviético en la Argentina" (4) (Lafiandra, 1955). Un ex senador chileno, afirmaba que "entre los partidarios del ex dictador, antes y después de la caída de éste, la infiltración comunista es intensa. Dijo que el comunismo argentino se había dividido, pues mientras parte estaba 'incrustada en el peronismo, la otra aparecía en la oposición"” (De Pie, 8/06/1956: 4). La juventud en general y los estudiantes en particular son un tema de interés para De Pie, ello es apreciable en los numerosos apartados que les dedica, donde la infiltración comunista entre los estudiantes es la motivación de dicha preocupación (5). Como comentamos anteriormente, a inicios de 1956 se produjeron variadas tensiones debido al decreto de diciembre del '55 en el que se habilitaba a la iniciativa privada a otorgar títulos. Esto, generó manifestaciones y reclamos por parte de los estudiantes, que se dividían entre quienes apoyaban al ministro de Educación Oro Maini y quienes se oponían terminantemente al decreto. Un mes luego del cese del conflicto, que ameritó la renuncia del ministro, el periódico se pregunta: "¿Y los disturbios del 'problema estudiantil' en nuestro país que tuvieron en zozobra hace un mes a todo el pueblo argentino, y a sus autoridades, a qué tendencia han respondido? ¿Cuáles fueron sus resultados? ¿Hubo infiltración comunista y socialista?” Y dejan al lector para la reflexión: "No pueden quedar en el olvido y en la indiferencia todos estos hechos y debemos volver a preguntarnos: ¿Qué pasa, hacia donde y por quienes es "guiado" el estudiantado sudamericano y argentino?" (De Pie, 22/06/1956: 4).

El conflicto educativo en torno al decreto quedó en suspenso durante el gobierno de la libertadora. Desde su firma en diciembre de 1955 hasta la promulgación de la Ley Domingorena, transcurrieron algunos años debido a los diversos cruces que el artículo 28 
generó (6). La ley universitaria provocó a diversos sectores de la ciudad y, como en otros lugares del país, existieron dos posiciones claras respecto a la ley: quienes adherían a la misma a favor de la libertad de enseñanza, los "libres"; y quienes se oponían a ley, los "laicos".

La Organización Estrada acude al principio de la educación como deber de la familia como uno de los fundamentos de la libertad de enseñanza: "todo se puede admitir menos cerrar los ojos o cegarse voluntariamente para no admitir una evidencia. Porque la enseñanza libre y sólo ella, respeta los derechos de todas las personas y de todas las familias". Otro de los argumentos utilizados a favor de la enseñanza libre fue la acusación de "totalitarismo" al monopolio estatal sobre lo educativo, argumento utilizado también por el periódico cuando se discutía sobre la ley 1420: “... no hay razón alguna, como no sea el sectarismo, la ignorancia (inexcusable, por supuesto) y la mentalidad totalitaria, para que la susodicha ley de enseñanza libre no pueda ser decretada" (El Rivadavia, 22/09/1958: 2). Ya en 1956 De Pie dejaba en claro su posición respecto de las universidades libres:

Es indispensable cambiar la estructura misma de la Universidad, y la primera medida radical a tomar es suprimir el monopolio estatal universitario. Debe permitirse y favorecerse, el nacimiento, desarrollo y fructificación de universidades privadas, que sean al mismo tiempo libres.

Las grandes universidades privadas, no sectarias suelen alcanzar un nivel intelectual mucho más elevado que las universidades del Estado, como se observa bien en los EE.UU e Inglaterra. En cambio las universidades del gobierno,... no están a cubierto de la política externa, que procuran aumentar el número de los que ingresan, rebajando las exigencias de su selección; aumentar los periodos de exámenes dándoles una importancia excesiva; disminuir la calidad de enseñanza y por fin, introducir los métodos de la baja política de comité en el gobierno de las Facultades y la elección de los profesores (De Pie, 4/05/1956: 4).

Se destaca la referencia a "universidades privadas", cuando la discusión propuesta desde el sector católico se presentaba en los términos de "universidades libres". Quienes se oponían a la ley si utilizaban el carácter privado de dichas instituciones para denunciar que no iban a responder a los intereses nacionales. Aparece como fundamento el alcance de un mayor nivel intelectual, que en el caso de las universidades estatales se ve perjudicado por la política, cuyos mecanismos van en detrimento de la calidad de enseñanza, en sintonía con el objetivo de la despolitización de la educación. Siguiendo a José Zanca (2006) y a Susana Bianchi (2015), el periódico es el portavoz del interés de la Iglesia, por un sistema educativo paralelo 
al estatal, que pueda ser controlado y administrado en su totalidad por la institución eclesiástica.

\section{Conclusiones}

A mediados de siglo XX y en el marco de la guerra fría donde la mirada política estaba centrada en la derrota de los totalitarismos, el comunismo creció como amenaza, siendo las masas obreras y estudiantiles, descuidadas en parte por la libertadora, vías posibles de infiltración. La preocupación del periódico De Pie era también el peronismo como un régimen totalitario, en sintonía con el objetivo de la Revolución Libertadora de evitar su regreso. Es por ello, que el conflicto educativo (la vuelta a la ley 1420, como el enfrentamiento entre "laicos y a libres" que generó la ley universitaria) se torna central en el periódico por el temor de la adhesión a ideas socialistas o comunistas por parte del estudiantado. En su papel de actor del sistema político cuestiona al gobierno no estar llevando a cabo el objetivo de la despolitización de la escuela y la Universidad. A su vez, que entiende a la educación fundamental para la defensa de la democracia, en condena de lo que había sido la "dictadura" y como barrera frente a la intromisión del totalitarismo. Otros puntos de crítica eran las acciones represivas y la política respecto al sector obrero.

La Organización Estrada, editora del periódico De Pie, se definió como una entidad sin carácter político y sin posición ideológica a favor ni en contra de ninguna fracción partidaria, si bien establecía una postura e influía en sus lectores haciendo críticas a las decisiones del gobierno provisional. Además las páginas del periódico expresaban una defensa del papel político de la Iglesia y la función rectora que cumple dentro de la sociedad, donde la educación resulta un ámbito primordial. En consecuencia, la Organización Estrada se posicionó a favor de la libertad de enseñanza y de la iniciativa privada, para terminar con el monopolio estatal, permitiendo mayor proyección y alcance de las instituciones educativas católicas.

Notas

(1) De Pie es una de las dos publicaciones católicas locales de las cuales tenemos referencia, la otra publicación es la revista Oro Negro editada por el Colegio Salesiano Deán Funes, que informaba novedades de la institución y notas de interés para la comunidad salesiana. La misma se publicó con regularidad desde 1929 hasta la década del 90'. El campo periodístico 
de la ciudad estaba compuesto además por el diario El Rivadavia que comenzó a editarse en 1915 hasta su última edición en 1965. Año en el que también dejó de publicarse el diario El Chubut, el cual había iniciado como semanario hacia 1921. Las publicaciones de tirada nacional que llegaban a la ciudad eran: La Prensa, La Nación y Caras y Caretas (Olivares, 2018).

(2) Otro actor social importante fue la Iglesia Católica, estrecha aliada del régimen militar. Pero su postura no fue uniforme ya que dependió de la adhesión personal de los sacerdotes mayoritariamente de la orden salesiana de Don Bosco- instalados en el sur. Algunos con militancia activa, difundiendo panfletos y realizando denuncias, tuvieron un claro compromiso con uno u otro bando (Ruffini, 2016: 13).

(3) Sobre los debates por la vuelta o no a la ley 1420 en la ciudad de Comodoro Rivadavia, véase: Autor/a, 2017; Autor/a y otro, 2017.

(4) Así se titula uno de los panfletos católicos que circularon desde fines de 1954, muchos de ellos fueron compilados en Lafiandra, 1955.

(5) Sobre juventud el periódico De Pie contiene las siguientes notas: De Pie, "¿Y nuestra juventud?", 27/04/1956: 2; De Pie, "Titulares que a diario vemos en cualquier informativo", 27/04/1956: 4; De Pie, "Estudiantiles", 11/05/1956: 1; De Pie, "Hacia dónde y por quién es 'guidado' nuestro estudiantado?", 25/05/1956: 1; De Pie, "Más sobre el problema estudiantil", 22/06/1956: 4; De Pie, “Juventud y esperanza”, julio 1956: 2.

(6) Sobre el conflicto "laica o libre", véase Brugaletta, 2011; Califa, 2009; Diez, 2016; Lichtmajer, 2004; Manzano, 2009.

\section{Bibliografía}

Ascolani, A. (2000). La revolución libertadora: Educación y Ciudadanía restringida (Argentina 1955-1958). En 23a reunión anual de ANPED, Caxambu, Brasil, del 24 al 28 de septiembre. Recuperado de http://www.anped.org.br/

AUTOR/A (2017). La educación durante la Revolución Libertadora en Comodoro Rivadavia: Entre la ley 1420 y la libertad de enseñanza. Actas de las XVI Jornadas Interescuelas/Departamentos de Historia. Recuperado de https://interescuelasmardelplata.com/actas/

AUTOR/A y OTRO (2017). Familia y educación en Comodoro Rivadavia. Los debates entre fines del primer peronismo y el inicio de la Revolución Libertadora. Historia Regional, 
36, enero-junio, pp. 19-28. Recuperado de http://historiaregional.org/ojs/index.php/historiaregional/article/view/124

Bianchi, S. (2015). Iglesia Católica y peronismo: La cuestión de la enseñanza religiosa (19461955). Estudios interdisciplinarios de América Latina y el Caribe, 3(2). Recuperado de http://eial.tau.ac.il/index.php/eial/article/view/1262/1289

Borrat, H. (1989). El periódico, actor del sistema político. Análisis, Cuadernos de comunicación y cultura, 12, pp. 67-80.

Brugaletta, F. (2011). La participación de los jóvenes católicos durante el conflicto "Laica o Libre". La Plata, 1958. Archivos de Ciencias de la Educación, 5(5).

Caimari, L. (2010). Perón y la Iglesia Católica. Religión, Estado y Sociedad en la Argentina (1943-1951). Buenos Aires: Emecé.

Califa, J. S. (2009) El movimiento estudiantil reformista frente al primer episodio de la "laica o libre" (mayo de 1956). Sociohistórica, Cuadernos del CISH 26, segundo semestre, pp. 51-79.

Diez, N. (2016). Es hora de jugar la Universidad". Una reconstrucción de las luchas reformistas en las calles platenses durante la "Laica o Libre" (septiembre-octubre de 1958). Revista Conflicto social, 9(15), enero a junio, pp. 130-157.

Galván, M. V. (2018). El anticomunismo transnacional y los gobiernos de facto de la "Libertadora": vínculos y ejes interpretativos. En Galván, M. V. y Osuna, M. F. (Comp.). La "Revolución Libertadora" en el marco de la Guerra Fría. La Argentina y el mundo durante los gobiernos de Lonardi y Aramburu (pp. 71- 90). Rosario: Prohistoria ediciones.

Lafiandra, F. (1955). Los panfletos. Su aporte a la Revolución Libertadora. Recopilación y comentario (2da edición). Buenos Aires: Editorial Itinerarium.

Lichtmajer, L. (2004). Laicos vs libres: El conflicto de 1958 en torno a la educación privada. Una aproximación a partir del GYMNASIUM de la U.N.T. Ponencia presentada en el primer Congreso sobre Historia de la Universidad Nacional de Tucumán.

Lida, M. y Fabris, M. D. (2016). La prensa católica y sus múltiples dimensiones: fuente, empresa editorial, actor social y político. Revista electrónica de Fuentes y Archivos, 7(7), Centro de Estudios Históricos "Prof. Carlos S. A. Segreti", Córdoba, Argentina, pp. 11-16.

Lionetti, L. (2006). La educación pública: escenario de conflictos y acuerdos entre católicos y liberales en la Argentina de fines del siglo XIX y comienzos del XX. Anuario de Estudios Americanos, 63(1), enero-junio, Sevilla, España, pp. 77-106. 
Manzano, V. (2009). Las batallas de los "laicos": movilización estudiantil en Buenos Aires, septiembre-octubre de 1958. Boletín del Instituto de Historia Argentina y Americana "Dr. Emilio Ravignani”, tercera serie, 3.

Martín, M. C. (2012). José Manuel Estrada: Estado, ciudadanía y cuestión social en el primer movimiento católico argentino. En Touris, C. y Ceva, M. (coord.). Los avatares de la "nación católica". Cambios y permanencias en el campo religioso de la Argentina contemporánea. Buenos Aires: Biblos.

Morresi, S. y Vicente, M. (2017). El enemigo íntimo: usos liberal conservadores del totalitarismo en la Argentina entre dos peronismos (1955-1973). Quinto Sol, 21(1), enero-abril.

Olivares, M. L. (2018). Prensa y peronismo en la Gobernación Militar de Comodoro Rivadavia: El diario El Chubut como articulador de la oposición al primer peronismo (1946-1955). (Tesis de maestría). Universidad Nacional de Quilmes.

Ruffini, M. (2016). Tiempos antiperonistas en la Patagonia argentina. La acción de las Comisiones Investigadoras durante la "Revolución Libertadora". Páginas, 8(16), pp. 61-81. Recuperado de http://revistapaginas.unr.edu.ar/index.php/RevPaginas

Spinelli, M. E. (2005). Los vencedores vencidos. El antiperonismo y la "revolución libertadora". Buenos Aires: Biblos.

Touris, C. (2007). Tensiones en el campo católico. La cuestión del peronismo después de 1955. Anuario IEHS, 22, p. 348. Recuperado de https://bit.ly/2kqSYZu

Vázquez Lorda, L. M. (2012). Intervenciones e iniciativas católicas en el ámbito familiar: Las Ligas de Madres y Padres de Familia (Argentina, 1950-1970). (Tesis de Maestría en investigación histórica). Universidad de San Andrés, Buenos Aires.

Vicente, M. (2018). El antitotalitarismo como clave antiperonista. Una geografía de los intelectuales liberal- conservadores en el posperonismo. En Galván, M. V. y Osuna, M. F. (Comp.). La "Revolución Libertadora" en el marco de la Guerra Fría. La Argentina y el mundo durante los gobiernos de Lonardi y Aramburu (pp. 131-152). Rosario: Prohistoria ediciones.

Zanca, J. (2006). Los intelectuales católicos y el fin de la cristiandad 1955-1966. Buenos Aires: Fondo de Cultura Económica. 